\title{
Portal vein embolization with ethylene-vinyl alcohol copolymer for contralateral lobe hypertrophy before liver resection: safety, feasibility and initial experience
}

\author{
Sébastien Gautier ${ }^{1}$, Olivier Chevallier ${ }^{1}$, Charles Mastier ${ }^{2}$, Philippe d'Athis $^{3}$, Nicolas Falvo ${ }^{1}$, Frank Pilleul ${ }^{2}$, \\ Marco Midulla ${ }^{1}$, Patrick Rat ${ }^{4}$, Olivier Facy ${ }^{4}$, Romaric Loffroy ${ }^{1}$ \\ ${ }^{1}$ Department of Vascular and Interventional Radiology, Image-Guided Therapy Center, ImViA Laboratory-EA 7535, François-Mitterrand University \\ Hospital, Dijon, France; ${ }^{2}$ Department of Interventional Radiology and Oncology, Léon Bérard Cancer Center, Lyon, France; ${ }^{3}$ Department of \\ Epidemiology and Biostatistics, François-Mitterrand University Hospital, Dijon, France; ${ }^{4}$ Department of Digestive and Oncologic Surgery, François- \\ Mitterrand University Hospital, Dijon, France
}

Correspondence to: Prof. Romaric Loffroy, MD, PhD, FCIRSE. Department of Vascular and Interventional Radiology, Image-Guided Therapy Center, ImViA Laboratory-EA 7535, François-Mitterrand University Hospital, 14 Rue Paul Gaffarel, BP 77908, 21079 Dijon Cedex, France. Email: romaric.loffroy@chu-dijon.fr.

Background: To report our preliminary experience with preoperative portal vein embolization (PVE) using liquid ethylene vinyl alcohol (EVOH) copolymer.

Methods: Retrospectively review of patients with primary or secondary liver malignancies scheduled for extensive hepatectomy after the induction of future liver remnant (FLR) hypertrophy by right or left PVE with EVOH as the only embolic agent between 2014 and 2018 at two academic centers. Cross-sectional imaging liver volumetry data obtained before and 3-6 weeks after PVE were used to assess the FLR volume (FLRV) increase, degree of FLR hypertrophy and the FLR kinetic growth rate (KGR).

Results: Twenty-six patients (17 males; mean age, 58.7 \pm 11 years; range, $32-79$ years) were included. The technical and clinical success rate was $100 \%$. PVE produced adequate FLR hypertrophy in all patients. Embolization occurred in all targeted portal branches and in no non-target vessels. The \%FLRV increased by $52.9 \% \pm 32.5 \%$ and the degree of FLR hypertrophy was $16.7 \% \pm 6.8 \%$. The KGR was $4.4 \% \pm 2.0 \%$ per week. Four patients experience minor complications after PVE which resolved with symptomatic treatment. The resection rate was $84.5 \%$. One patient died during surgery for reasons unrelated to PVE.

Conclusions: Preoperative PVE with EVOH copolymer is feasible, safe, and effective in inducing FLR hypertrophy.

Keywords: Portal vein embolization (PVE); Ethylene vinyl alcohol copolymer; Onyx ${ }^{\circledR}$; hepatectomy; liver cancer; future liver remnant (FLR)

Submitted Jun 27, 2020. Accepted for publication Sep 25, 2020.

doi: 10.21037/qims-20-808

View this article at: http://dx.doi.org/10.21037/qims-20-808

\section{Introduction}

The optimal treatment for patients with primary or secondary liver malignancies is tumor resection with negative margins (1). However, extensive hepatectomy carries a risk of life-threatening liver failure (2). Portal vein occlusion performed before hepatectomy takes advantage of the unique regenerative potential of hepatic tissue by redirecting blood toward the liver that will remain after surgery, or future liver remnant (FLR), which then undergoes hypertrophy (3). This technique has made 
hepatectomy possible in patients with very small preocclusion FLRs. Occlusion can be achieved by portal vein ligation or portal vein embolization (PVE). PVE has produced high technical and clinical success rates with low morbidity and, compared to ligation, larger FLR increases and shorter hospital stays (4-7).

No randomized trials are available to determine which embolic agent is optimal for PVE. A mixture of $\mathrm{N}$-butylcyanoacrylate (NBCA) and ethiodized oil is safe and effective according to a 2018 review of Level IIa cohort studies (8). However, the rapid polymerization and strong adhesive properties of NCBA may result in unpredictable embolization, with a risk of complications such as non-target vessel occlusion, venous migration, and catheter blockage or retention (9). Moreover, the strong inflammatory reaction induced by NBCA may raise challenges during the surgical resection (10).

Ethylene-vinyl alcohol $(\mathrm{EVOH})$ copolymer $\left(\mathrm{Onyx}{ }^{\circledR}\right.$ LES, Covidien, Plymouth, $\mathrm{MN}$ ) is a non-adhesive liquid embolic agent whose slower solidification rate compared to NBCA may improve embolization predictability. $\mathrm{EVOH}$ is dissolved in dimethyl sulfoxide (DMSO), and micronized tantalum powder is suspended in the mixture to provide contrast for fluoroscopy. The occlusion obtained is permanent. $\mathrm{EVOH}$ has been found effective and safe for treating cerebral arteriovenous malformations, type II endoleaks, hemoptysis, renal angiomyolipomas, and for peripheral hemostasis (11-17). When used for PVE, EVOH seemed to result in faster growth of FLR compared to other embolic agents (18).

Here, our objective was to assess the efficacy and safety of PVE performed with $\mathrm{EVOH}$ only, based on a retrospective review of patients managed at two centers.

\section{Methods}

\section{Ethical statement}

According to institutional policy, approval from our Institutional Review Board was not required and the informed patient consent requirement was waived owing to the investigation's retrospective nature. All methods were carried out in accordance with relevant guidelines and regulations.

\section{Patients}

The databases of two academic centers were searched for patients scheduled between April 2014 and June 2018 for major hepatectomy to treat primary or secondary liver cancer, with previous PVE due to a small FLR. In each patient, the decision to perform hepatic resection surgery after PVE was taken by a multidisciplinary tumor board including a radiologist, a surgeon, and an oncologist. At both centers, the smallest acceptable FLR was $25 \%$ in patients without and $40 \%$ in patients with an underlying liver disease (19-23).

\section{Investigations related to PVE}

\section{Pre-embolization workup}

Abdominal computed tomography (CT) or magnetic resonance imaging (MRI) was performed in each patient before PVE (24) (Figure 1). The portal phase was used to assess portal vein anatomy, hepatic segmentation as described by Couinaud, the extent of hepatic and extrahepatic involvement by the malignancy, and the presence of tumor in the FLR (25). Total tumor volume (TV), FLR tumor volume (FLRTV), embolized liver tumor volume (ELTV), FLR volume (FLRV), total liver volume (TLV), and embolized liver volume (ELV) were measured after exclusion of the large vessels and major fissures. The percentage of FLR (\%FLR) was computed as the tumor-free FLR volume over the tumor-free liver volume according to the following formula (26).

\section{Post-embolization liver volumetry}

The above-defined volumes were measured again by CT or MRI 3 to 4 weeks after PVE (Figure 1). Two parameters were used to assess the hypertrophy response (7): the degree of FLR hypertrophy (DH) and the \%FLRV increase were calculated by the following formulas (27):

$$
D H=(\% \text { FLR after PVE }-\% \text { FLR before PVE })
$$

$$
\% \text { FLRV increase }=\frac{(\% \text { FLR after PVE }-\% \text { FLR before PVE })}{\% \text { FLR before PVE }} \times 100 \%
$$



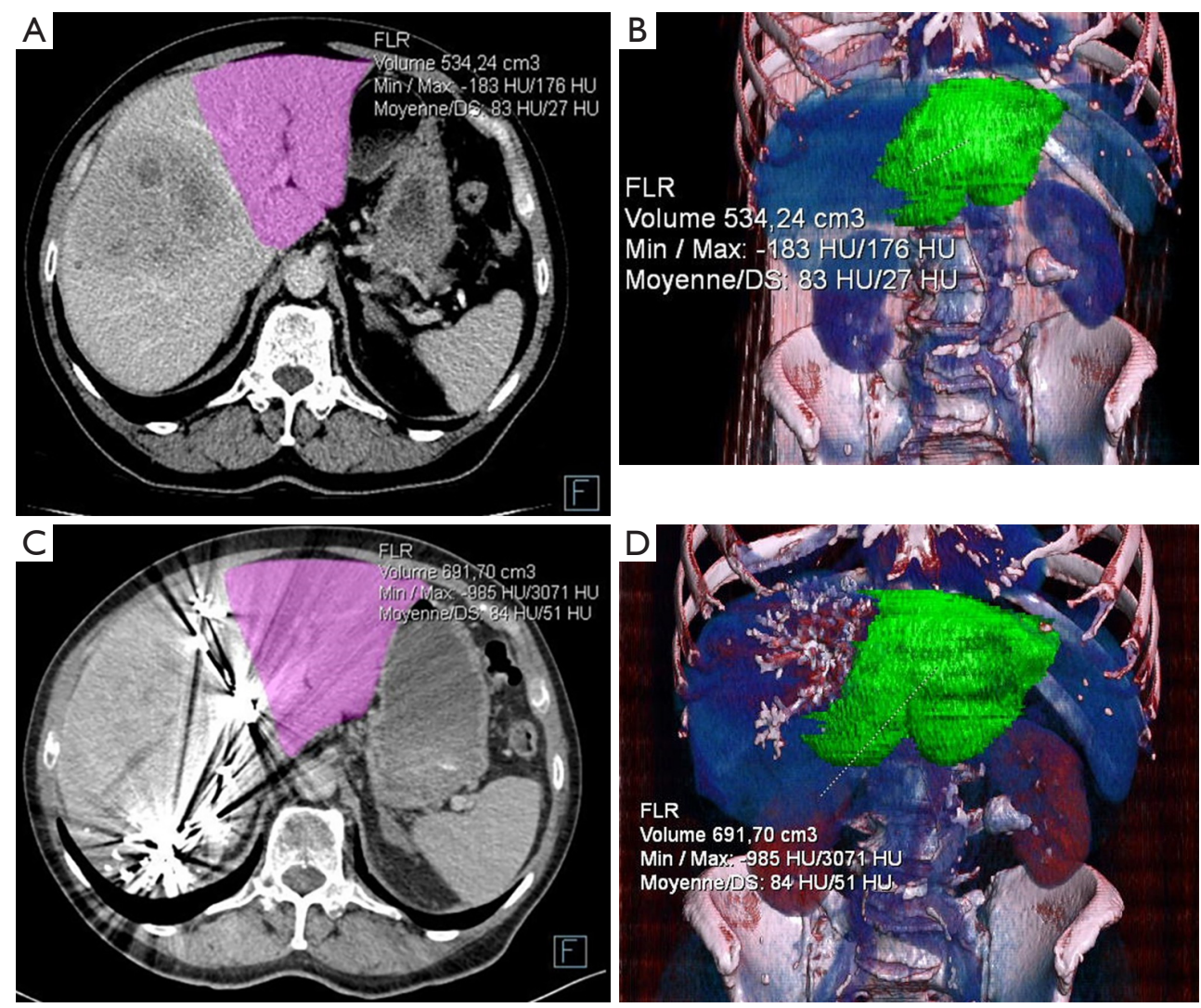

Figure 1 CT-based liver volumetry calculation before/after PVE with EVOH in a 74-year-old man with right-sided hepatocellular carcinoma showing important FLR hypertrophy after PVE. FLR was manually delimited on axial images at the portal venous phase and an automated algorithm interpolated all slices to obtain the volume of the region of interest (in pink) and a 3D volume rendering reconstruction (in green). (A,B) FLR before right PVE procedure was $534 \mathrm{~mL}$ (22\% of the total liver volume). (C,D) FLR after right PVE procedure was $691 \mathrm{~mL}$ (41.6\% of the total liver volume). The \%FLR increase was $87.6 \%$ and the degree of hypertrophy of FLR was $19.4 \%$. Beam hardening white artifacts after PVE related to EVOH copolymer liver distribution are well visualized in the right portal vein branches on axial images. No complication following PVE occurred. PVE, portal vein embolization; EVOH, ethylene-vinyl alcohol; FLR, future liver remnant.

The pace of FLR growth was assessed by computing the kinetic growth rate (KGR) as $\mathrm{DH}$ over the time elapsed since PVE, as follows (28):

$$
K G R=\frac{D H}{\text { time elapsed since PVE }}
$$

\section{PVE technique}

Patients were admitted for 2 days and PVE was performed under light general anesthesia. The PVE procedures in the study patients were done by two experienced hepatobiliary interventional radiologists. The Onyx ${ }^{\circledR}$ liquid embolization system included a $1.5-\mathrm{mL}$ vial of Onyx ${ }^{\circledR}$, a $1.5-\mathrm{mL}$ vial of DMSO, and three 1-mL delivery syringes. Before use, the vial contents were homogenized on a mixer for at least 15 minutes by gentle rotation according to the manufacturer's instructions. The vial was used immediately after mixing to ensure even distribution of the tantalum and, therefore, reliable fluoroscopy visualization. Depending on the required depth of EVOH penetration into the embolization site, either Onyx ${ }^{\circledR}-18\left(6 \%\right.$ EVOH) or Onyx ${ }^{\circledR}-$ $34(8 \% \mathrm{EVOH})$ was used.

A 21-Gauge Chiba needle was introduced into a peripheral branch of the contralateral portal system under ultrasound guidance. According to the Seldinger technique, a 6-French introducer sheath was inserted into the main portal vein, which was then opacified to show the venous anatomy and look for a fistula, whose presence 

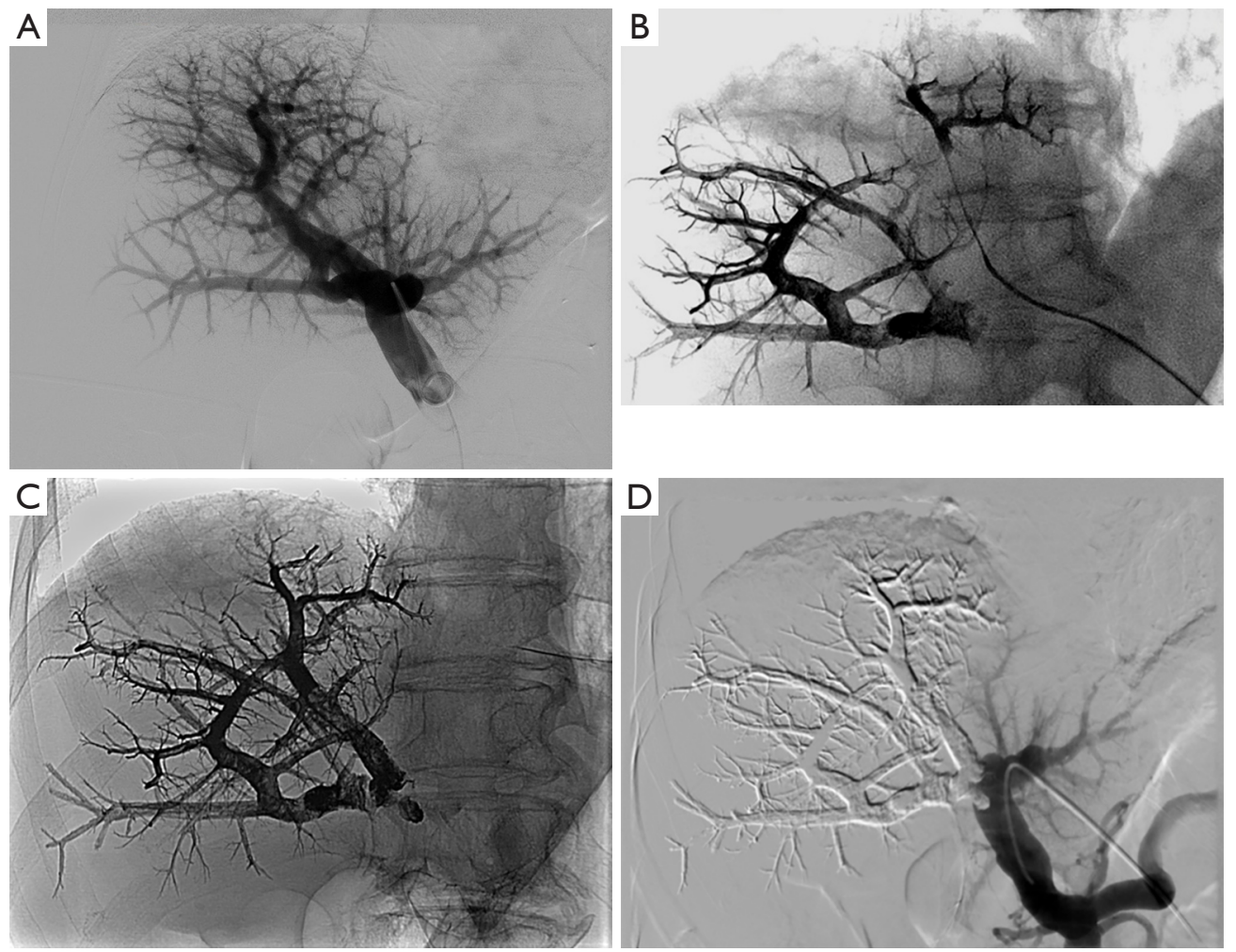

Figure 2 Preoperative right PVE in the same 74-year-old man with right-sided hepatocellular carcinoma. (A) Initial portography from the main portal vein through the left side showing normal anatomy; (B) fluoroscopic image during selective embolization of portal vein branches through a microcatheter showing filling of portal branches with $\mathrm{EVOH}$; (C) fluoroscopic control demonstrating the distribution of highly radiopaque EVOH copolymer into the right portal vein branches; (D) final post-PVE portography from the main portal vein showing complete and successful occlusion of all right portal vein branches. PVE, portal vein embolization; EVOH, ethylene-vinyl alcohol.

would contraindicate the procedure. A standard coaxial system composed of a guidewire and a DMSO-compatible 2.7-French microcatheter (Progreat ${ }^{\circledR}$, Terumo, Japan) was used to selectively catheterize target second-order portal vein branches. The microcatheter was flushed with saline and DMSO was injected to fill the microcatheter dead space, thus preventing $\mathrm{EVOH}$ solidification in the catheter lumen. As soon as the microcatheter reached the most distal portal branches, EVOH was injected under fluoroscopic guidance, at a rate below $0.3 \mathrm{~mL} / \mathrm{min}$ (Figure 2).

The EVOH first traveled in the anterograde direction, along the normal venous flow, then occluded the vein downstream of the microcatheter, inducing reflux along the microcatheter, which ensured embolization of narrow portal vessels without requiring selective catheterization. Catheter removal was achieved easily as long as the $\mathrm{EVOH}$ reflux along the tip did not exceed $1 \mathrm{~cm}$. After occlusion of all the small branches, the microcatheter tip was moved to a more proximal position, and a further $\mathrm{EVOH}$ injection was performed. This procedure was repeated in each target portal segmental branch. EVOH was administered until all target portal vessels were occluded. The proximal trunk (left or right) was occluded last, leaving a 1-cm non-occluded segment to facilitate surgical ligation during hepatectomy. Portal venography was then performed to check completeness of embolization. Finally, during removal of the sheath, the puncture track was embolized with sterile absorbable gelatin sponge to ensure hemostasis (Curaspon ${ }^{\circledR}$ Cura Medical, Assendelft, The Netherlands).

After the procedure, patients underwent thorough physical examinations for evidence of adverse events, as well as liver function tests and blood cell counts $(4,29)$. Further investigations were performed as dictated by the clinical situation. 
Table 1 Baseline characteristics of the 26 study patients

\begin{tabular}{|c|c|}
\hline Data & $\begin{array}{c}\text { No. of patients (\%) or } \\
\text { mean SD (range) }\end{array}$ \\
\hline Demographics & $26(100.0)$ \\
\hline Age (years) & $58.711[32-79]$ \\
\hline Male gender & $17(65.4)$ \\
\hline Liver tumor type & $26(100.0)$ \\
\hline Primary tumor & $12(46.1)$ \\
\hline Hepatocellular carcinoma & $8(30.8)$ \\
\hline Healthy liver & $4(15.4)$ \\
\hline Viral hepatitis C & $2(7.7)$ \\
\hline Non-alcoholic steatohepatitis & $1(3.8)$ \\
\hline Alcoholic cirrhosis & $1(3.8)$ \\
\hline Cholangiocarcinoma & $3(11.5)$ \\
\hline Extrahepatic & $2(7.7)$ \\
\hline Intrahepatic & $1(3.8)$ \\
\hline Hemorrhagic hepatic adenoma & $1(3.8)$ \\
\hline Secondary tumor & $14(53.8)$ \\
\hline Metastases & $13(50.0)$ \\
\hline Colorectal cancer & $10(38.5)$ \\
\hline Kidney cancer & $1(3.8)$ \\
\hline Breast cancer & $1(3.8)$ \\
\hline Malignant paraganglioma & $1(3.8)$ \\
\hline Peribiliary cysts & $1(3.8)$ \\
\hline Underlying liver disease & $10(38.5)$ \\
\hline Chemotherapy & $5(19.2)$ \\
\hline Cirrhosis & $2(7.7)$ \\
\hline Fibrosis & $1(3.8)$ \\
\hline Steatosis & $1(3.8)$ \\
\hline Diabetes & $1(3.8)$ \\
\hline Preoperative bile duct drainage & $2(7.7)$ \\
\hline Future liver remnant segments & $26(100.0)$ \\
\hline $1+2+3$ & $17(65.4)$ \\
\hline $1+2+3+4$ & $6(23.1)$ \\
\hline $2+3+4$ & $1(3.8)$ \\
\hline $2+3$ & $1(3.8)$ \\
\hline $6+7$ & $1(3.8)$ \\
\hline
\end{tabular}

No., number; SD, standard deviation.

\section{Assessment criteria}

Technical success was defined as complete occlusion of all portal branches feeding the liver segments to be resected (23). Clinical success was defined as achieving an FLR of at least $25 \%$ in patients without, and at least $40 \%$ in patients with, underlying liver disease (23).

Clinical symptoms and laboratory parameter alterations after PVE were recorded. The following post-hepatectomy data were collected: resection margins, hospital stay length, postoperative complications, and day-90 mortality due to liver failure.

\section{Statistical analysis}

Statistical Triomphe ${ }^{\circledR}$ software developed at the medical statistics unit of our university was used. Volumes were described as mean $\pm \mathrm{SD}$ and categorical variables as $\mathrm{n}$ (\%). Liver volumetry variables before and after PVE were compared by applying Student's $t$ test. P values $<0.05$ were considered significant, and $95 \%$ confidence intervals $(95 \%$ CIs) were computed.

\section{Results}

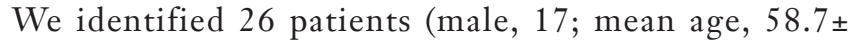
11 years; range, 32-79) meeting our selection criteria. Twenty-two patients were managed in the $1^{\text {st }}$ academic center and 4 patients in the $2^{\text {nd }}$ center. Twelve patients with primary liver malignancy and 14 patients with secondary liver malignancy were treated. Table 1 reports their main characteristics before PVE.

Table 2 provides details on the PVE procedures and the numbers of patients managed with Onyx ${ }^{\circledR}-18$ and Onyx ${ }^{\circledR}-$ 34. Complete embolization of the right portal tree was performed in 25 patients. In the remaining patient, the embolization involved the left portal tree with extension to segments V and VIII. Simultaneous endoscopic bile duct drainage was performed in 2 patients with hilar cholangiocarcinoma $(30,31)$. Figure 3 reports the number of Onyx ${ }^{\circledR}$ vials used (mean, $12.0 \pm 4.8$; range, 5-25).

\section{PVE outcomes}

Both the technical success rate and the clinical success rate of PVE were $100 \%$. Mean time from PVE to postembolization liver volumetry was $28.5 \pm 9.5$ days (range, 
Table 2 PVE procedure and follow-up after PVE

\begin{tabular}{|c|c|}
\hline Data & $\begin{array}{l}\text { No. of patients (\%) or } \\
\text { mean SD (range) }\end{array}$ \\
\hline PVE procedure & $26(100.0)$ \\
\hline \multicolumn{2}{|l|}{ Side } \\
\hline Right PVE & $25(96.2)$ \\
\hline Right PVE & $23(88.5)$ \\
\hline Right PVE extended to segment 4 & $2(11.5)$ \\
\hline Left PVE & $1(3.8)$ \\
\hline Type of Ony $x^{\circledR}$ used & $26(100.0)$ \\
\hline Onyx $x^{\circledR} 18$ only & $16(61.5)$ \\
\hline Onyx ${ }^{\mathbb{1}} 34$ only & 5 (19.2) \\
\hline Both & $5(19.2)$ \\
\hline Complications & $3(11.5)$ \\
\hline Minor complications & $4(15.4)$ \\
\hline Transient fever & $2(7.7)$ \\
\hline Transient pain & $2(7.7)$ \\
\hline Non-target embolization & $0(0)$ \\
\hline Major complications & $0(0)$ \\
\hline Hepatic surgery procedure & $22(84.6)$ \\
\hline Type of surgery & $22(84.6)$ \\
\hline Right hepatectomy & $6(27.3)$ \\
\hline Right hepatectomy extended to S4 & $14(63.6)$ \\
\hline Right hepatectomy extended to S1 & $1(4.5)$ \\
\hline Left hepatectomy extended to S5/S8 & $1(4.5)$ \\
\hline Cancellation of hepatic resection & $4(15.4)$ \\
\hline Tumor progression on $\mathrm{CT}$ & $2(7.7)$ \\
\hline Metastases at laparotomy & $2(7.7)$ \\
\hline Inadequate FLR growth & $0(0)$ \\
\hline Resection margins & $22(84.6)$ \\
\hline Ro & $20(90.9)$ \\
\hline $\mathrm{R} 1$ & $1(4.5)$ \\
\hline $\mathrm{Rx}$ & $1(4.5)$ \\
\hline \multicolumn{2}{|l|}{ Complications } \\
\hline \multicolumn{2}{|l|}{ Major complications } \\
\hline Death during surgery & $1(4.2)$ \\
\hline Minor complications & 5 (20.9) \\
\hline Abscess & $4(16.7)$ \\
\hline Biliary peritonitis & $1(4.2)$ \\
\hline Postoperative hospital stay (days) & $12.8 \pm 13.8[8-27]$ \\
\hline Mortality rate at 3 months & $1(3.8)$ \\
\hline
\end{tabular}

${ }^{\dagger}$, resection margins were not examined because the patient died during surgery. PVE, portal vein embolization; S, segment; No., number; SD, standard deviation; $\mathrm{CT}$, computed tomography; FLR, future liver remnant.

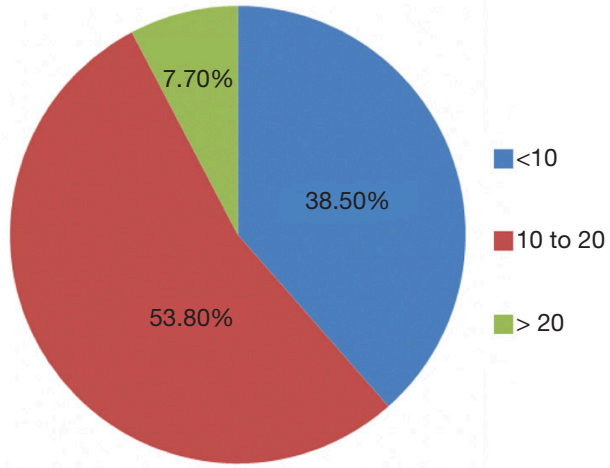

Figure 3 Number of Onyx's vials used for PVE in the study. Mean number of vials was $12.0 \pm 4.8$ (range, 5-25). PVE, portal vein embolization.

9-47 days). FLRV increased from 704.6 $\pm 248.2 \mathrm{~mL}$ (median, 640.5 mL; range, 434.0-1,265.0 mL) before PVE to $956.9 \pm 270.5 \mathrm{~mL}$ (median, $915.0 \mathrm{~mL}$; range, 521.0 $1,904.0 \mathrm{~mL})$ after PVE. The \%FLR increased from $35.5 \% \pm 9.2 \%$ (median, $33.8 \%$ ) to $52.2 \% \pm 8.1 \%$ (median, $51.2 \%$ ). The \%FLRV increase was $52.9 \% \pm 32.5 \%$ (median, $44.2 \%$; range, $11.8-153.3 \%$ ). DH was $16.7 \pm 6.9$ (median, 15.6; range, 5.6-36.5). The mean KGR was $4.4 \% \pm 2.0 \%$ per week (median, $3.6 \%$; range, $1.9-11.1 \%$ ). In the 10 patients who had an underlying hepatopathy, the \%FLRV increase was $45.4 \% \pm 39.7 \%$ (median, $39.7 \%$; range, $13.9-153.3 \%$ ), the DH was $14.5 \pm 8.4$ (median, 14.5 ; range, $10.0-17.1$ ) and the mean KGR was $3.6 \% \pm 1.9 \%$ per week (median, $3.2 \%$; range, 1.9-4.4\%). Data are summarized in Table 3.

\section{Safety data}

During the 2-day hospital stay, 4 patients experienced minor symptoms of post-embolization syndrome (grade B in the Society of Interventional Radiology classification) (32): 2 had low-grade fever and 2 others mild abdominal discomfort (Table 2). Acetaminophen was sufficient to control the symptoms in all patients. No major complications were recorded. Table 4 shows the main liver function test results before and after PVE. No significant change was noted.

\section{Liver resection}

Data are summarized in Table 2. Resection was not performed in 2 patients, due to extensive disease in the FLR or to the development of extrahepatic disease between the 
Table 3 Radiological liver volumetry results of PVE

\begin{tabular}{|c|c|c|c|c|c|}
\hline Parameters (mL) & Before PVE & After PVE & $\Delta \pm \mathrm{SD}$ & $95 \% \mathrm{Cl}$ & $P$ value \\
\hline ELTV & $195.0 \pm 294.6$ & $186.9 \pm 265.6$ & $-8.2 \pm 79.4$ & -40.14 to 23.69 & 0.602 \\
\hline FLRTV & $5.3 \pm 18.0$ & $5.6 \pm 15.6$ & $0.3 \pm 3.4$ & -1.14 to 1.63 & 0.718 \\
\hline TV & $200.4 \pm 300.9$ & $192.5 \pm 269.3$ & $-8.0 \pm 81.2$ & -40.63 to 24.68 & 0.621 \\
\hline FLRV & $704.6 \pm 248.2$ & $956.9 \pm 270.5$ & $252.3 \pm 200.0$ & 171.94 to 332.67 & $9.71 .10^{-07 *}$ \\
\hline$\% F L R$ & $35.5 \pm 9.2$ & $52.2 \pm 8.1$ & $16.7 \pm 6.9$ & 13.93 to 19.47 & $3.85 .10^{-12 *}$ \\
\hline
\end{tabular}

Data before and after PVE, available in all patients, are expressed as means $\pm \mathrm{SD}$. * $\mathrm{P}<0.05$ was considered significant. $\mathrm{PVE}$, portal vein embolization; TLV, total liver volume; ELTV, embolized liver tumor volume; FLRTV, future liver remnant tumor volume; TV, total tumor volume; ELV, embolized liver volume; FLRV, future liver remnant volume; \%FLR, percentage of FLR; $\Delta$, difference between after and before PVE; SD, standard deviation; $\mathrm{Cl}$, confidence interval.

Table 4 Liver laboratory function tests before and after PVE

\begin{tabular}{lcccc}
\hline Parameters & Before PVE & After PVE & $95 \% \mathrm{Cl}$ & P value \\
\hline ALT (U/L) & $135 \pm 221$ & $110 \pm 173$ & -28.13 to 80.13 & 0.320 \\
AST (U/L) & $113 \pm 198$ & $86 \pm 143$ & -30.18 to 82.98 & 0.334 \\
Total bilirubin (umol/L) & $19 \pm 23$ & $21 \pm 29$ & -8.11 to 3.84 & 0.457 \\
\hline
\end{tabular}

Data before and after PVE, available in 15 patients only, are expressed as means $\pm \mathrm{SD}$. $\mathrm{P}<0.05$ was considered significant. ALT, alanine transaminase; AST, aspartate transaminase; PVE, portal vein embolization; SD, standard deviation; Cl, confidence interval.

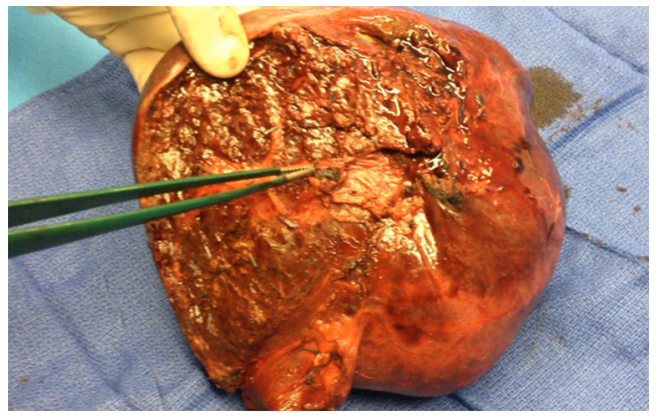

Figure 4 Macroscopic view of right hepatectomy. The tip of the tissue plier shows blackish material occluding right portal vein corresponding to EVOH. EVOH, ethylene-vinyl alcohol.

PVE procedure and the post-PVE imaging studies. Mean time from PVE and surgery was $44.5 \pm 18.3$ days (range, 19-85 days). Of the 24 patients who had surgery, 2 had previously unsuspected metastases identified during the procedure and consequently did not undergo the planned hepatectomy procedure. Thus, 4 (15.4\%) patients did not undergo major hepatectomy.
Four patients had postoperative complications classified as grade III according to Dindo-Clavien, i.e., requiring radiological or surgical intervention (33). One patient died during surgery due to extensive bleeding from a vena cava injury unrelated to the PVE procedure. No patient experienced fatal liver failure.

Pathological examination of the embolized liver showed dark blue-to-black material in the lumen of the targeted portal tree with no evidence of recanalization in all patients. An inflammatory reaction was evidenced in the tissue surrounding the embolized vessels (Figure 4).

\section{Discussion}

In our retrospective review of 26 patients with liver malignancies managed between 2014 and 2018, PVE performed using EVOH to induce FLR hypertrophy was technically successful in every case and consistently increased the FLR volume to at least $40 \%$ or $25 \%$ of total liver volume in patients with and without underlying liver disease, respectively. No major complications of 
PVE were recorded. Four patients experienced mild postembolization symptoms that responded to acetaminophen. To our knowledge, this is the largest study reporting results of preoperative PVE with the use of $\mathrm{EVOH}$ as the only embolic agent.

Several agents are available for PVE. Recommendations issued by the Cardiovascular and Interventional Radiological Society of Europe indicate that some embolic agents should be avoided due to a high rate of portal vein recanalization or to limited efficiency in inducing liver hypertrophy (23). A mixture of NBCA and ethiodized oil induced substantial FLR hypertrophy with low morbidity rates in several studies $(4,5,8,34)$. Onyx ${ }^{\circledR}$ has produced good outcomes when used for various peripheral interventions $(15,17)$. A study in a pig model reported in 2012 established the feasibility of PVE with Onyx ${ }^{\circledR}$ (35). During PVE with NBCA, EVOH has been found useful for occluding portal vein branches for which the use of NBCA was deemed to carry a high risk of non-target embolization (36). Our $84.5 \%$ surgical resection rate is consistent with the $75.9 \%$ rate reported in a recent meta-analysis of PVE with NCBA (8). The \%FLRV increase was also similar in our study and the meta-analysis. In a study of 41 patients, $\mathrm{EVOH}$, used in 11 patients, produced faster growth of the S2/3 segments compared to ethiodized oil ( $\mathrm{n}=10)$, polyvinyl alcohol $(n=8)$, and ligation $(n=12)(18)$. In keeping with this finding, KGR values above $2 \%$ have been reported to correlate with favorable surgical outcomes, and the KGR of $4.4 \pm 2.0$ per week in our study was thus well into the safety zone (28). Thus, EVOH, with a FLRV increase of $52.9 \%$ in our study, might be among the most effective agents for inducing liver hypertrophy as compared to the existing literature (Table 5) (37-55). One explanation could be the distal and inflammatory nature of EVOH embolization. It is worth noting that 2 of our patients underwent postPVE imaging early, on day 9, yet had \%FLRV increases of $13.9 \%$ and $31.3 \%$, indicating a very short PVE response time, in keeping with earlier data (56). Finally, a good response to PVE was seen in the 10 patients who had an underlying liver disease predicted to slow the pace of liver regeneration.

Minor complications of PVE have been reported in 20\% to $25 \%$ of patients, compared to $15 \%$ in our population $(4,5,8,23)$. No major PVE-related complications were recorded. More specifically, no patient experienced posthepatectomy liver failure or fatal liver failure within 90 days after surgery.

EVOH copolymer is a plastic polymer that is used dissolved in DMSO and solidifies gradually upon contact with blood. DMSO is potentially toxic, and its metabolites are excreted through the lungs and kidneys. A case of acute respiratory distress syndrome related to DMSO has been reported (57). A slow Onyx ${ }^{\circledR}$ injection rate of $0.3 \mathrm{~mL} / \mathrm{min}$ is recommended to avoid vasospasm. However, vasospasm does not occur at the portal vein, and the amount of DMSO contained in the microcatheter dead space is well below the toxic threshold. Therefore, an injection rate of up to $0.5 \mathrm{~mL} / \mathrm{min}$ can be used for PVE. Advantages of EVOH over NBCA include a slower time to solidification of about 5 min that improves embolization predictability, absence of adherence to the vessel or catheter walls allowing multiple injections to achieve full penetration, greater cohesiveness, less endothelial inflammation, and better fluoroscopic visibility (58). These properties virtually eliminate the risk of non-target embolization. No cases of catheter adhesion, obstruction, or trapping were recorded in our study. As with NBCA, vessel occlusion is permanent. Furthermore, PVE with $\mathrm{EVOH}$ could be more standardized and homogeneous than with NBCA. Indeed, when using glue, the NBCA/ lipiodol ratio varies from center to center depending on operator comfort. This might potentially lead to discrepancies in liver hypertrophy.

Compared to Onyx ${ }^{\circledR}-34$, Onyx ${ }^{\circledR}-18$ has lower viscosity and therefore penetrates deeper into the portal tree. Onyx ${ }^{\circledR}-$ 34 is useful for embolizing more proximal sites near the portal trunk. The high radiodensity of Onyx ${ }^{\circledR}$ can generate beam-hardening artifacts that may interfere with the quality of post-PVE CT imaging. However, no artifacts occur with MRI, which visualizes EVOH as low endoluminal signal on T1- and T2-weighted sequences, without artifacts.

Onyx $^{\circledR}$ has three main disadvantages. The DMSO injection is painful, and complete immobility of the patient must be maintained during fluoroscopy. However, PVE is usually performed under light general anesthesia regardless of the embolic agent used, with no pain. Second, Onyx ${ }^{\circledR}$ is considerably more expensive than NBCA (59). Finally, the fluoroscopy time may be longer with Onyx ${ }^{\circledR}$ than with other embolic agents but general anesthesia allows for faster injection.

Two methods can be used for PVE with Onyx ${ }^{\circledR}$. In the first method, after the first injection, the reflux along the catheter solidifies within 2-3 min, after which a second injection can only travel in the anterograde direction into the target vessels. In the second method, the catheter tip is advanced as far as possible in the portal tree and a continuous $\mathrm{Onyx}^{\circledR}$ injection at a steady rate is then 
Table 5 Impact of embolic agent used for PVE on the hypertrophy of FLR reported in the literature

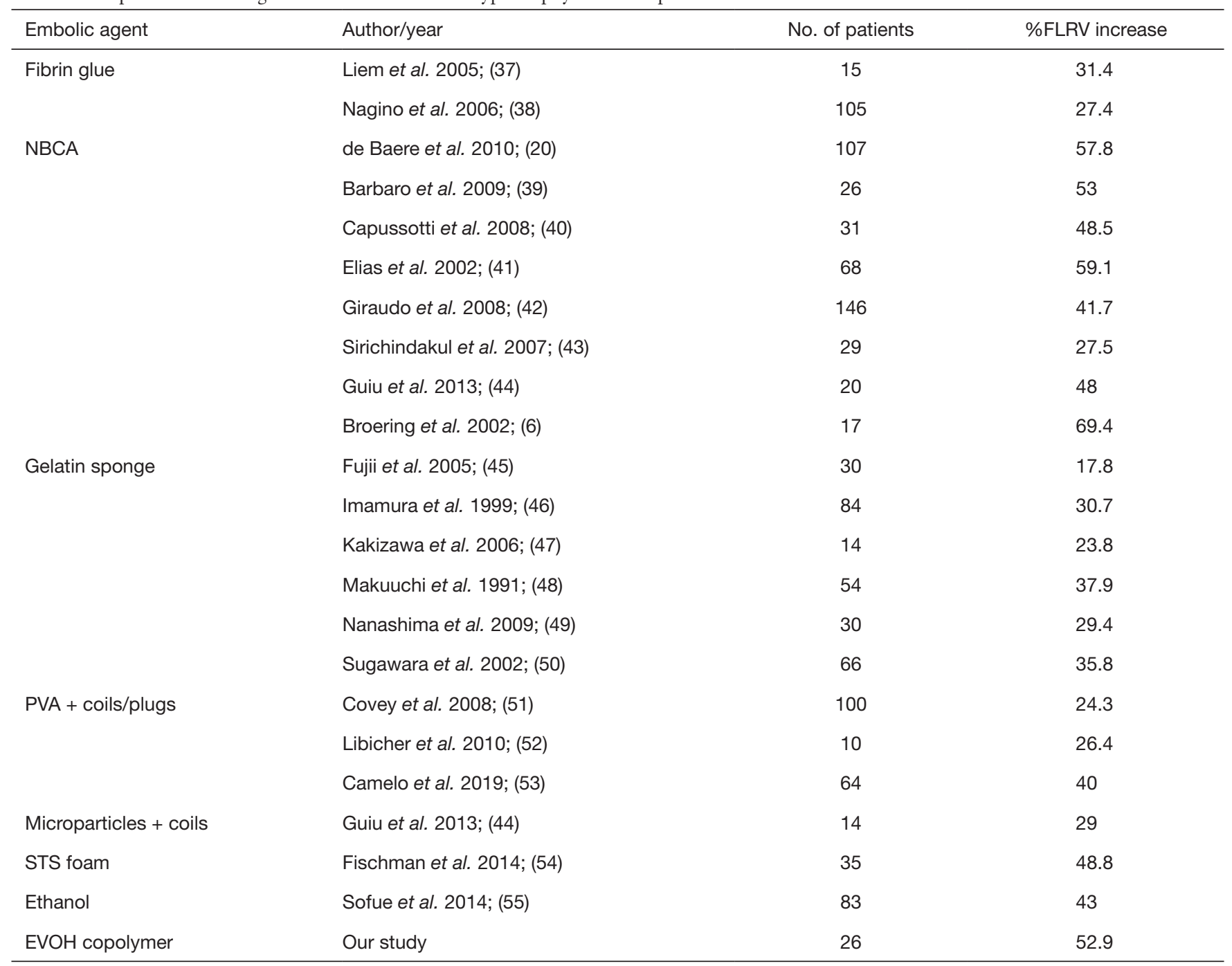

NBCA, N-butyl cyanoacrylate; PVA, polyvinyl alcohol; STS, sodium tetradecyl sulfate; EVOH, ethylene-vinyl alcohol; No., number; PVE, portal vein embolization; \%FRLV, percentage of future liver remnant volume.

performed until reflux along the catheter and retrograde penetration of the $\mathrm{EVOH}$ into the portal tree branches occur, producing a smooth lava-flow like pattern with no fragmentation. The catheter tip is then retracted along about $1 \mathrm{~cm}$ and a further injection is performed. Thus, the EVOH does not need to be injected directly into the target site, and both small and large vessels of any configuration can be embolized without selective catheterization (36).

Lastly, the use of EVOH was as easy to use ipsilaterally as it was contralaterally. Indeed, the site of puncture did not matter for using EVOH. By contralateral approach, tract embolization with gelfoam is the rule, as with any other embolic agents. By ipsilateral approach, the portal branch which is initially punctured for PVE has to be embolized last, with no risk of sticking the catheter as compared to NBCA.

The main limitations of our study are the retrospective design and small sample of patients. Body mass index was not available for computing the standardized FLR volume (60). Hepatobiliary scintigraphy was not performed, limiting the amount of information on liver function (56). Nevertheless, the $100 \%$ technical and clinical success rates and the absence of major complications deserve note and warrant further studies of EVOH for PVE compared to other embolic agents. 


\section{Conclusions}

In conclusion, PVE with EVOH alone was feasible, safe, and effective in inducing FLR hypertrophy. Despite higher cost, this liquid embolic agent is very promising in such a setting. Further work is needed to determine the role for EVOH PVE in the treatment strategy for patients with liver malignancies.

\section{Acknowledgments}

Funding: None.

\section{Footnote}

Conflicts of Interest: All authors have completed the ICMJE uniform disclosure form (available at http://dx.doi. org/10.21037/qims-20-808). RL serves as a Deputy Editor for Quantitative Imaging in Medicine and Surgery. The other authors have no conflicts of interest to declare.

Ethical Statement: According to institutional policy, approval from our Institutional Review Board was not required owing the retrospective nature of the study. Written informed consent from the patient for publication of this study and any accompanying images was waived.

Open Access Statement: This is an Open Access article distributed in accordance with the Creative Commons Attribution-NonCommercial-NoDerivs 4.0 International License (CC BY-NC-ND 4.0), which permits the noncommercial replication and distribution of the article with the strict proviso that no changes or edits are made and the original work is properly cited (including links to both the formal publication through the relevant DOI and the license). See: https://creativecommons.org/licenses/by-nc-nd/4.0/.

\section{References}

1. Scheele J, Altendorf-Hofmann A, Stangl R, Schmidt K. Surgical resection of colorectal liver metastases: gold standard for solitary and radically resectable lesions. Swiss Surg 1996;4:4-17.

2. Kauffmann R, Fong Y. Post-hepatectomy liver failure. Hepatobiliary Surg Nutr 2014;3:238-46.

3. Alizai PH, Haelsig A, Bruners P, Ulmer F, Klink CD, Dejong CHC, Neumann UP, Schmeding M. Impact of liver volume and liver function on posthepatectomy liver failure after portal vein embolization. A multivariable cohort analysis. Ann Med Surg (Lond) 2017;25:6-11.

4. Abulkhir A, Limongelli P, Healey AJ, Damrah O, Tait P, Jackson J, Habib N, Jiao LR. Preoperative portal vein embolization for major liver resection: a meta-analysis. Ann Surg 2008;247:49-57.

5. van Lienden KP, van den Esschert JW, de Graaf W, BBipat S, Lameris JS, van Gulik M, van Delden OM. Portal vein embolization before liver resection: a systematic review. Cardiovasc Intervent Radiol 2013;36:25-34.

6. Broering DC, Hillert C, Krupski G, Fischer L, Mueller L, Achilles EG, Schulte am Esch J, Rogiers X. Portal vein embolization versus portal vein ligation for induction of hypertrophy of the future liver remnant. J Gastrointest Surg 2002;6:905-13.

7. Robles R, Marin C, Lopez-Conesa A, Capel A, PerezFlores D, Parilla P. Comparative study of right portal vein ligation versus embolisation for induction of hypertrophy in two-stage hepatectomy for multiple bilateral colorectal liver metastases. Eur J Surg Oncol 2012;38:586-93.

8. Wajswol E, Jazmati T, Contractor S, Kumar A. Portal vein embolization utilizing n-butyl cyanoacrylate for contralateral lobe hypertrophy prior to liver resection: a systematic review and meta-analysis. Cardiovasc Intervent Radiol 2018;41:1302-12.

9. Hill H, Chick JFB, Hage A, Srinivasa RN. N-butyl cyanoacrylate embolotherapy: techniques, complications, and management. Diagn Interv Radiol 2018;24:98-103.

10. de Baere T, Roche A, Elias D, Lasser P, Lagrange C, Bousson V. Preoperative portal vein embolization for extension of hepatectomy indications. Hepatology 1996;24:1386-91.

11. Weber W, Kis B, Siekmann R, Jans P, Laumer R, Kühne D. Preoperative embolization of intracranial arteriovenous malformations with Onyx. Neurosurgery 2007;61:244-52; discussion 252-4.

12. Jamieson RW, Bachoo P, Tambyraja AL. Evidence for ethylene-vinyl-alcohol-copolymer liquid embolic agent as a monotherapy in treatment of endoleaks. Eur J Vasc Endovasc Surg 2016;51:810-4.

13. Ayx I, Müller-Wille R, Wohlgemuth WA, Pfeifer M, Lepiorz M, Hubauer H, Goessmann H, Stroszczynski C, Zorger N. Treatment of acute hemoptysis by bronchial artery embolization with the liquid embolic agent ethylene vinyl alcohol copolymer. J Vasc Interv Radiol 2017;28:825-31.

14. Urbano J, Paul L, Cabrera M, Alonso-Burgos A, Gómez D. Elective and emergency renal angiomyolipoma 
embolization with ethylene vinyl alcohol copolymer: feasibility and initial experience. J Vasc Interv Radiol 2017;28:832-9.

15. Kolber MK, Shukla PA, Kumar A, Silberzweig JE. Ethylene vinyl alcohol copolymer (Onyx®) embolization for acute hemorrhage: a systematic review of peripheral applications. J Vasc Interv Radiol 2015;26:809-15.

16. Né R, Chevallier O, Falvo N, Facy O, Berthod PE, Galland C, Gehin S, Midulla M, Loffroy R. Embolization with ethylene vinyl alcohol copolymer (Onyx $\left.{ }^{\circledR}\right)$ for peripheral hemostatic and non-hemostatic applications: a feasibility and safety study. Quant Imaging Med Surg 2018;8:280-90.

17. Saeed Kilani M, Izaaryene J, Cohen F, Varoquaux A, Gaubert JY, Louis G, Jacquier A, Bartoli JM, Moulin G, Vidal V. Ethylene vinyl alcohol copolymer (Onyx®) in peripheral interventional radiology: indications, advantages and limitations. Diagn Interv Imaging 2015;96:319-26.

18. Biggemann L, Uhlig J, Streit U, Sack H, Guo XC, Jung C, Ahmed S, Lotz J, Müller-Wille R, Seif Amir Hosseini A. Future liver remnant growth after various portal vein embolization regimens: a quantitative comparison. Minim Invasive Ther Allied Technol 2020;29:98-106.

19. Denys A, Lacombe C, Schneider F, Madoff DC, Doenz F, Qanadli SD, Halkic N, Sauvanet A, Vilgrain V, Schnyder P. Portal vein embolization with n-butyl cyanoacrylate before partial hepatectomy in patients with hepatocellular carcinoma and underlying cirrhosis or advanced fibrosis. J Vasc Interv Radiol 2005;16:1667-74.

20. de Baere T, Teriitehau C, Deschamps F, Catherine L, Rao P, Hakime A, Auperin A, Goere D, Elias D, Hechelhammer L. Predictive factors for hypertrophy of the future remnant liver after selective portal vein embolization. Ann Surg Oncol 2010;17:2081-9.

21. Shindoh J, Tzeng CW, Aloia TA, Curley SA, Zimmitti G, Wei SH, Huang SY, Mahvash A, Gupta S, Wallace MJ, Vauthey JN. Optimal future liver remnant in patients treated with extensive preoperative chemotherapy for colorectal liver metastases. Ann Surg Oncol 2013;20:2493-2500.

22. Farges O, Belghiti J, Kianmanesh R, Regimbeau JM, Santoro R, Vilgrain V, Denys A, Sauvanet A. Portal vein embolization before right hepatectomy: prospective clinical trial. Ann Surg 2003;237:208-17.

23. Denys A, Bize P, Demartines N, Deschamps F, De Baere T; Cardiovascular and Interventional Radiological Society of Europe. Quality improvement for portal vein embolization. Cardiovasc Intervent Radiol 2010;33:452-6.
24. Gotra A, Chartrand G, Vu KN, Vandenbroucke-Menu F, Massicotte-Tisluck K, de Guise JA, Tang A. Comparison of MRI- and CT-based semiautomated liver segmentation: a validation study. Abdom Radiol (NY) 2017;42:478-89.

25. Couinaud C. Liver anatomy: portal (and suprahepatic) or biliary segmentation. Dig Surg 1999;16:459-67.

26. Piron L, Deshayes E, Escal L, Souche R, Herrero A, Pierredon-Foulongne MA, Assenat E, le Lam N, Quenet F, Guiu B. Portal vein embolization: Present and future. Bull Cancer 2017;104:407-16.

27. Ribero D, Abdalla EK, Madoff DC, Donadon M, Loyer EM, Vauthey JN. Portal vein embolization before major hepatectomy and its effects on regeneration, resectability and outcome. Br J Surg 2007;94:1386-94.

28. Shindoh J, Truty MJ, Aloia TA, Curley SA, Zimmitti G, Huang SY, Mahvash A, Gupta S, Wallace MJ, Vauthey JN. Kinetic growth rate after portal vein embolization predicts posthepatectomy outcomes: toward zero liver-related mortality in patients with colorectal liver metastases and small future liver remnant. J Am Coll Surg 2013;216:201-9.

29. Kodama Y, Shimizu T, Endo H, Miyamoto N, Miyasaka K. Complications of percutaneous transhepatic portal vein embolization. J Vasc Interv Radiol 2002;13:1233-7.

30. Guiu B, Bize P, Demartines N, Lesurtel M, Denys A. Simultaneous biliary drainage and portal vein embolization before extended hepatectomy for hilar cholangiocarcinoma: preliminary experience. Cardiovasc Intervent Radiol 2014;37:698-704.

31. Nimura Y, Kamiya J, Kondo S, Nagino M, Uesaka K, Oda K, Sano T, Yamamoto H, Hayakawa N. Aggressive preoperative management and extended surgery for hilar cholangiocarcinoma: Nagoya experience. J Hepatobiliary Pancreat Surg 2000; 7:155-62.

32. Sacks D, McClenny TE, Cardella JF, Lewis CA. Society of interventional radiology clinical practice guidelines. J Vasc Interv Radiol 2003;14:S199-S202.

33. Dindo D, Demartines N, Clavien PA. Classification of surgical complications: a new proposal with evaluation in a cohort of 6336 patients and results of a survey. Ann Surg 2004;240:205-13.

34. Loffroy R, Favelier S, Chevallier O, Estivalet L, Genson PY, Pottecher P, Gehin S, Krausé D, Cercueil JP. Preoperative portal vein embolization in liver cancer: indications, techniques and outcomes. Quant Imaging Med Surg 2015;5:730-9.

35. Smits MLJ, Vanlangenhove P, Sturm EJ, van den Bosch MA, Hav M, Praet M, Vente MA, Snaps FR, Defreyne L. 
Transsinusoidal portal vein embolization with ethylene vinyl alcohol copolymer (Onyx®): a feasibility study in pigs. Cardiovasc Intervent Radiol 2012;35:1172-80.

36. Breguet R, Boudabbous S, Pupulim LF, Becker CD, Rubbia-Brandt L, Toso C, Ronot M, Terraz S. Ethylene vinyl alcohol copolymer for occlusion of specific portal branches during preoperative portal vein embolisation with n-butyl-cyanoacrylate. Eur Radiol 2018;28:4810-7.

37. Liem MS, Liu CL, Tso WK, Lo CM, Fan ST, Wong J. Portal vein embolisation prior to extended right-sided hepatic resection. Hong Kong Med J 2005;11:366-72.

38. Nagino M, Kamiya J, Nishio H, Ebata T, Arai T, Nimura Y. Two hundred forty consecutive portal vein embolizations before extended hepatectomy for biliary cancer: surgical outcome and long-term follow-up. Ann Surg 2006;243:364-72.

39. Barbaro B, Caputo F, Tebala C, Di Stasi C, Vellone M, Giuliante F, Nuzzo G, Bonomo L. Preoperative right portal vein embolisation: indications and results. Radiol Med 2009; 114:553-70.

40. Capussotti L, Muratore A, Baracchi F, Lelong B, Ferrero A, Regge D, Delpero JR. Portal vein ligation as an efficient method of increasing the future liver remnant volume in the surgical treatment of colorectal metastases. Arch Surg 2008;143:978-82.

41. Elias D, Ouellet JF, de Baère T, Lasser P, Roche A. Preoperative selective portal vein embolization before hepatectomy for liver metastases: long-term results and impact on survival. Surgery 2002;131:294-9.

42. Giraudo G, Greget M, Oussoultzoglou E, Rosso E, Bachellier P, Jaeck D. Preoperative contralateral portal vein embolization before major hepatic resection is a safe and efficient procedure: a large single institution experience. Surgery 2008;143:476-82.

43. Sirichindakul B, Nonthasoot B, Taesombat W, Supaphol J, Nivatvongs S, Janchai A, Tantivatana J. Role of portal vein embolization in hepatobiliary malignancy. Hepatogastroenterology 2007;54:2297-300.

44. Guiu B, Bize P, Gunthern D, Demartines N, Halkic N, Denys A. Portal vein embolization before right hepatectomy: improved results using n-butyl-cyanoacrylate compared to microparticles plus coils. Cardiovasc Intervent Radiol 2013;36:1306-12.

45. Fujii Y, Shimada H, Endo I, Takeda K, Takahashi T, Tanaka K, Togo S. Improvement of prognosis for colorectal metastases by major hepatectomy after portal vein embolization. Hepatogastroenterology 2005;52:1792-4.
46. Imamura H, Shimada R, Kubota M, Matsuyama Y, Nakayama A, Miyagawa S, Makuuchi M, Kawasaki S. Preoperative portal vein embolization: an audit of 84 patients. Hepatology 1999;29:1099-105.

47. Kakizawa H, Toyota N, Arihiro K, Naito A, Fujimura Y, Hieda M, Hirai N, Tachikake T, Matsuura N, Murakami Y, Itamoto T, Ito K. Preoperative portal vein embolization with a mixture of gelatin sponge and iodized oil: efficacy and safety. Acta Radiol 2006;47:1022-8.

48. Makuuchi M, Kosuge T, Lygidakis NJ. New possibilities for major liver surgery in patients with Klatskin tumors or primary hepatocellular carcinoma--an old problem revisited. Hepatogastroenterology 1991;38:329-36.

49. Nanashima A, Sumida Y, Abo T, Nonaka T, Takeshita H, Hidaka S, Sawai T, Yasutake T, Sakamoto I, Nagayasu T. Clinical significance of portal vein embolization before right hepatectomy. Hepatogastroenterology 2009;56:773-7.

50. Sugawara Y, Yamamoto J, Higashi H, Yamasaki S, Shimada K, Kosuge T, Takayama T, Makuuchi M. Preoperative portal embolization in patients with hepatocellular carcinoma. World J Surg 2002;26:105-10.

51. Covey AM, Brown KT, Jarnagin WR, Brody LA, Schwartz L, Tuorto S, Sofocleous CT, D'Angelica M, Getrajdman GI, DeMatteo R, Kemeny NE, Fong Y. Combined portal vein embolization and neoadjuvant chemotherapy as a treatment strategy for resectable hepatic colorectal metastases. Ann Surg 2008;247:451-5.

52. Libicher M, Herbrik M, Stippel D, Poggenborg J, Bovenschulte H, Schwabe H. Portal vein embolization using the amplatzer vascular plug II: preliminary results. Rofo 2010;182:501-6.

53. Camelo R, Luz JH, Gomes FV, Coimbra E, Costa NV, Bilhim T. Portal vein embolization with PVA and coils before major hepatectomy: Single-center retrospective analysis in sixty-four patients. J Oncol 2019;2019:4634309.

54. Fischman AM, Ward TJ, Horn JC, Kim E, Patel RS, Nowakowski FS, Lookstein RA. Portal vein embolization before right hepatectomy or extended right hepatectomy using sodium tetradecyl sulfate foam: technique and initial results. J Vasc Interv Radiol 2014;25:1045-53.

55. Sofue K, Arai Y, Shimada K, Takeuchi Y, Kobayashi T, Satake M, Sugimura K. Right portal vein embolization with absolute ethanol in major hepatic resection for hepatobiliary malignancy. Br J Surg 2014;101:1122-8.

56. Guiu B, Quenet F, Escal L, Bibeau F, Piron L, Rouanet P, Fabre JM, Jacquet E, Denys A, Kotzki PO, Verzilli D, Deshayes E. Extended liver venous deprivation before 
major hepatectomy induces marked and very rapid increase in future liver remnant function. Eur Radiol 2017;27:3343-52.

57. Murugesan C, Saravanan S, Rajkumar J, Prasad J, Banakal S, Muralidhar K. Severe pulmonary oedema following therapeutic embolization with Onyx for cerebral arteriovenous malformation. Neuroradiology 2008;50:439-42.

58. Loffroy R, Guiu B, Cercueil JP, Krausé D. Endovascular therapeutic embolisation: an overview of occluding agents and their effects on embolised tissues. Curr Vasc

Cite this article as: Gautier S, Chevallier O, Mastier C, d'Athis P, Falvo N, Pilleul F, Midulla M, Rat P, Facy O, Loffroy R. Portal vein embolization with ethylene-vinyl alcohol copolymer for contralateral lobe hypertrophy before liver resection: safety, feasibility and initial experience. Quant Imaging Med Surg 2021;11(2):797-809. doi: 10.21037/qims-20808
Pharmacol 2009;7:250-63.

59. Loffroy R, Favelier S, Genson PY, Guiu B. Onyx® for embolization of life-threatening hemoptysis: a promising but luxury embolic agent! Cardiovasc Intervent Radiol 2012;35:221.

60. Vauthey JN, Chaoui A, Do KA, Bilimoria MM, Fenstermacher MJ, Charnsangavej C, Hicks M, Alsfasser G, Lauwers G, Hawkins IF, Caridi J. Standardized measurement of the future liver remnant prior to extended liver resection: Methodology and clinical associations. Surgery 2000;127:512-9. 